\title{
Echocardiographic Finding of Non-Obstructive Fibromuscular Band in Right Atrium
}

Trivedi JV*

Department of Medicine, Gujarat Adani Institute of Medical Science, Bhuj Gujarat, India

\section{Introduction}

The purpose of this case report was to present an echocardiographic finding of non-obstructivefibromuscular band in Right atrium dividing RA in to two chambers.patient was referred to Gujarat Adani Institute of Medical Science for management of systemic Hypertension. We have come across a fibromuscular band in right Atrium a patient in whom we carried out Transthoracic echocardiography for hypertension.

\section{Case Report}

Male aged 28, was referred to our medical out door for control and management of Hypertension. This patient was asymptomatic and was having active life. His family history did not revealed cardiovascular disease and no known causes of premature sudden cardiac death among close relatives. Neither he had undergone any surgeries or treatment in past. He had no relevant past medical history and physical examination was normal. His systemic blood pressure in right radial artery in sitting posture was $180 / 100 \mathrm{mmHg}$. Resting 12-lead electrocardiogram was normal All his serum chemistry related to Renal Function, s. uric acid, fundus examination, Renal Arterial Doppler VMA examination Chest X-Ray was normal. His ultra sonography examination was normal. His Fasting Blood Sugar and Postprandial Sugar were normal. Serum Lipid Profile, Homocystine, collagen work up was normal.2 -D Echocardiogram showed Right atrium divided into two chambers by an incomplete fibromuscular band, a thin incompete diaphragm in all echocardiographic views. The Tricuspid valve appeared mildly dysplastic with no regurgitation. Pulmonary artery pressure was estimated to be $20 \mathrm{mmHg}$. The patient was asymptomatic. Suspected diagnosis of non-obstructive cortriatriatum was suspected. Patient did not have any signs of right ventricular dysfunction or Right ventricular enlargement [1-10]. His left side of heart i.e. Left Atrium, Left Ventricle, Mitral valve, Inter Atrial Septum and Pulmonary veins were normal. Aorta, interventricular septum and Aortic valves didnot show any congenital abnormalities. Thus diagnosis of isolated non-obstructive Fibromusclar band in RA was confirmed (Figure 1).

Cortriatrium was first time was seen in 1868.It is a congenital anomaly in which the left atrium or right atrium is divided into two

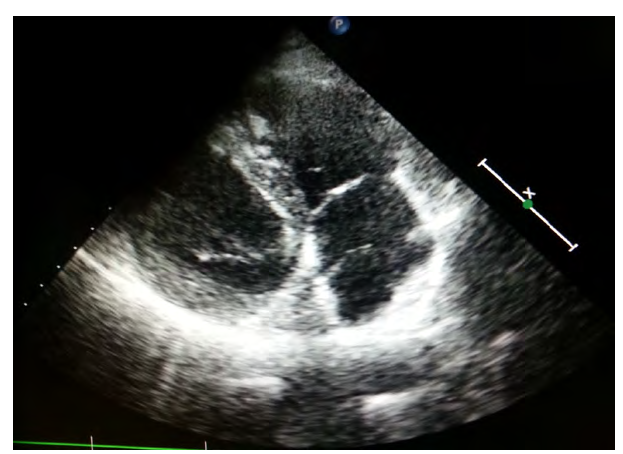

Figure 1: Apical $4 \mathrm{CH}$ view which shows fibromuscular band in RA. chambers by a fold of tissue, a membrane or a fibro muscular band., The upper part of the corresponding atrium receives venous blood, whereas the lower portion is in contact with the atrioventricular valve The membrane that separates the atrium into two parts may be a complete imperforated band or may have one or more holes for blood to pass [11-20]. Cortriatriatum sinister is a congenital heart defect characterised by a fibro muscular membrane in left atrium. Where as in Cortriatrium dexter Right atrium has fibro muscular bandit is diagnosed in paediatric age group of patients.and adult cases are extremely rare.Symptoms will depend on the type and degree of obstruction like Tricuspid stenosis. The membrane may be complete or may contain one or more opening of varying size. It can be treated surgically and has no medical treatment. Other congenital conditions like tetralogy of Fallot, double outlet right ventricle, coarctation of the aorta, partial anomalous pulmonary venous connection, persistent left superior vena cava with unroofed coronary sinus, ventricular septal defect, atrioventricular cushion defects and common atrioventricular canal., Asplenia or polysplenia have been reported in adults. In adults, cortriatriatum is frequently an isolated finding (Figures 2 and 3 ) [21-30].

\section{Conclusion}

This case suggest the increasingly frequency of diagnosis of adults with congenital heart disease due to availability of 2D Echocardiography

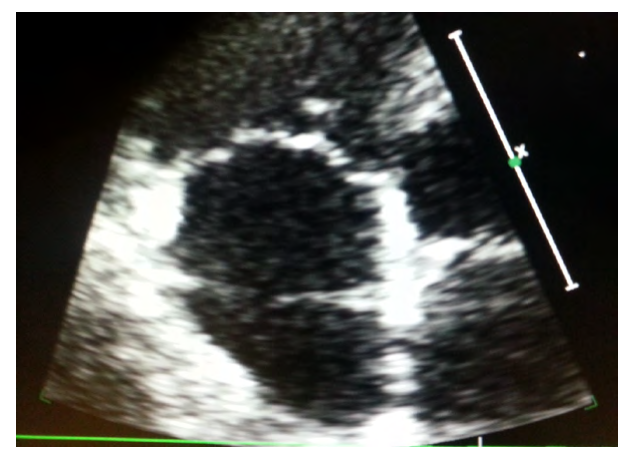

Figure 2: Selective two chamber view with rotation of transduer shows band with whole in bandin.

*Corresponding author: Trivedi JV, Head of Department and Professor of Medicine, Gujarat Adani Institute of Medical Science, Bhuj Gujarat, India; Tel: +9102832-246417/18; E-mail: drjvtrivedi@rediffmail.com

Received June 09, 2016; Accepted June 17, 2016; Published August 05, 2016

Citation: Trivedi JV (2016) Echocardiographic Finding of Non-Obstructive Fibromuscular Band in Right Atrium. J Vasc Med Surg 4: 280. doi: 10.4172/23296925.1000280

Copyright: ( 2016 Trivedi JV. This is an open-access article distributed under the terms of the Creative Commons Attribution License, which permits unrestricted use, distribution, and reproduction in any medium, provided the original author and source are credited. 
Citation: Trivedi JV (2016) Echocardiographic Finding of Non-Obstructive Fibromuscular Band in Right Atrium. J Vasc Med Surg 4: 280. doi: $10.4172 / 2329-6925.1000280$

Page 2 of 2

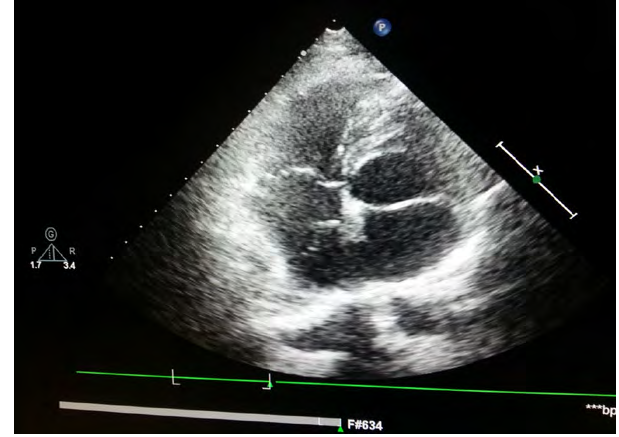

Figure 3: Apical $4 \mathrm{CH}$ view shows band in RA in incomplete form.

even in asymptomatic patient. Adult cases of congenital heart disease are mainly found through echocardiographic examinations. It leads to questions for further research, whether to call it Cortriatrium dexter or not? IT was an important and rare disease which was diagnosed accidentally [31-41].

\section{References}

1. Church CWS (1868) Congenital malformation of heart: abnormal septum in left auricle. Trans Path Soz 19: 188-190.

2. Griffith TW (1903) Note on a Second Example of Division of the Cavity of the Left Auricle into Two Compartments by a Fibrous Band. J Anat Physiol 37: 255-257.

3. Anderson $\mathrm{RH}$ (1992) Understanding the nature of congenital division of the atrial chambers. Br Heart J 68: 1-3.

4. Richardson JV, Doty DB, Siewers RD (1981) Cor triatriatum (subdivided left atrium). J Thorac Cardiovasc Surg 81: 232-238.

5. Trento A, Zuberbuhler JR, Anderson RH, Park SC, Siewers RD, et al. (1988) Divided right atrium (prominence of the eustachian and thebesian valves). J Thorac Cardiovasc Surg. 96: 457- 463.

6. Garcia J, Tandon R, Lucas RV Jr (1975) Cor triatriatum: study of 20 cases. Am J Cardiol. Jan. 35: 59-66.

7. Niwayama G, (1960) Cor triatriatum. Am Heart J 59: 291-317.

8. Jennings RB, Innes BJ (1977) Subtotal cor triatriatum with left partial anomalous pulmonary venous return. Successful surgical repair in an infant. J Thorac Cardiovasc Surg. 74: 461-466.

9. Tuccillo B, Stumper O, Hess J (1992) Transoesophageal echocardiographic evaluation of atrial morphology in children with congenital heart disease. Eur Heart J 13: 223-231.

10. Wolf WJ (1986) Diagnostic features and pitfalls in the two-dimensional echocardiographic evaluation of a child with cor triatriatum. Pediatr Cardiol 6: 211-213.

11. Beller B, Childers R, Eckner F (1967) Cor triatriatum in the adult. Complicated by mitral insufficiency and aortic dissection. Am J Cardiol 19: 749-754.

12. Chen Q, Guhathakurta S, Vadalapali G (1999) Cor triatriatum in adults: three new cases and a brief review. Tex Heart Inst J 26: 206-210.

13. Ludomirsky A, Erickson C, Vick GW (1990) Transesophageal color flow Doppler evaluation of cor triatriatum in an adult. Am Heart J 120: 451-455.

14. O'Murchu B, Seward JB (1995) Images in cardiovascular medicine. Adult congenital heart disease. Obstructive and nonobstructive cortriatriatum. Circulation 92: 35-74

15. Peleato PA, Perez PMP, Arroyo RJR (2006) Cor triatriatum in adults: intracardiac echocardiography. Rev Esp Cardiol 59: 1-67.

16. Slight RD, Nzewi OC, Mankad PS (2004) Echocardiographic diagnosis of cor triatriatum sinister in the adult. Heart 90: 63.

17. Slight RD, Nzewi OC, Sivaprakasam R (2003) Cor triatriatum sinister presenting in the adult as mitral stenosis. Heart 89: 26.

18. Hamdan R, Mirochnik N, Celermajer D, Nassar P, Iserin L (2010) Cor Triatriatum
Sinister diagnosed in adult life with three dimensional transesophagea echocardiography. BMC Cardiovasc Disord 28: 54

19. Biglioli P, Gherli T, Mastroni P, Puliga V, Alamanni F (1984) A case of left cor triatriatum associated with an interatrial defect with partial anomalous venous return. Panminerva Med 26: 197-198.

20. Gharagozloo F, Bulkley BH, Hutchins GM (1977) A proposed pathogenesis of cor triatriatum: impingement of the left superior vena cava on the developing left atrium. Am Heart J 94: 618-626.

21. Gheissari A, Malm JR, Bowman FO Jr, Bierman FZ (1992) Cor triatriatum sinistrum: one institution's 28-year experience. Pediatr Cardiol 13: 85-88.

22. Ibrahim T, Schreiber K, Dennig K, Schömig A, Schwaiger M (2003) Images in cardiovascular medicine: Assessment of cor triatriatum sinistrum by magnetic resonance imaging. Circulation 108: e107.

23. Loeffler $E$ (1949) Unusual malformation of the left atrium; pulmonary sinus Arch Pathol (Chic) 48: 371-376.

24. Smith OI, Silverman NH, Oldershaw P, Lincoln C, Shinebourne EA (1984) Cor triatriatum sinistrum. Diagnostic features on cross sectional echocardiography. Br Heart J 51: 211-219.

25. Parsons CG (1950) Cor triatriatum; concerning the nature of an anomalous septum in the left auricle. Br Heart J 12: 327-38.

26. Thilenius OG, Bharati S, Lev M (1976) Subdivided left atrium: an expanded concept of cor triatriatum sinistrum. Am J Cardiol 37: 743-52.

27. Belder MA, Argano V, Burrell CJ (1992) Cor triatriatum sinister, not mitra stenosis, in an adult with previous Sydenham's chorea: diagnosis and preoperative assessment by cross sectional echocardiography. Br Heart $\mathrm{J} 68$ : 9-11.

28. Alboliras ET, Edwards WD, Driscoll DJ, Seward JB (1987) Cor triatriatum dexter: two-dimensional echocardiographic diagnosis. J Am Coll Cardiol 9: 334-337.

29. Burton DA, Chin A, Weinberg PM, Pigott JD (1987) Identification of cor triatriatum dexter by two-dimensional echocardiography. Am J Cardiol 160: 409-410.

30. Dobbertin A, Warnes CA, Seward JB (1995) Cor triatriatum dexter in an adult diagnosed by transesophageal echocardiography: a case report. J Am Soc Echocardiogr 8: 952-957.

31. Fiorilli R, Argento G, Tomasco B, Serino W (1995) Cor triatriatum dexter diagnosed by transesophageal echocardiography. J Am Soc Echocardiogr 8: 952-957.

32. Joe BN, Amin PM, Woodard PK (2003) Case 56: cor triatriatum dexter Radiology 226: 701-5.

33. Hansing CE, Young WP, Rowe GG (1972) Cor triatriatum dexter. Persistent right sinus venosus valve. Am J Cardiol 30: 559-564.

34. Savas V, Samyn J, Schreiber TL, Hauser A, O'Neill WW (1991) Cor triatriatum dexter: recognition and percutaneous transluminal correction. Cathe Cardiovasc Diagn 23: 183-186.

35. Trakhtenbroit A, Majid P, Rokey R (1990) Cor triatriatum dexter: antemortem diagnosis in an adult by cross sectional echocardiography. Br Heart J 63: 314-6.

36. Thakrar A, Shapiro MD, Jassal DS, Neilan TG, King ME (2007) Cor triatriatum the utility of cardiovascular imaging. Can J Cardiol 23: 143-145.

37. Vallakati A, Nerella N, Chandra P, Sadiq A, Shani J (2012) Incidental diagnosis of cor triatriatum in 2 elderly patients. J Am Coll Cardiol 59: e43.

38. Schluter M, Langenstein BA, Thier W, Schmiegel WH, Krebber HJ, et al. (1983) Transesophageal two-dimensional echocardiography in the diagnosis of cor triatriatum in the adult. J Am Coll Cardiol 2: 1011-1015.

39. Buchholz S, Jenni R (2001) Doppler echocardiographic findings in 2 identical variants of a rare cardiac anomaly, "subtotal" cor triatriatum: a critical review of the literature. J Am Soc Echocardiogr 14: 846-849.

40. Corno AF, Bron C, von Segesser LK (1999) Divided right atrium. Diagnosis by echocardiography, and considerations on the functional role of the Eustachian valve. Cardiol Young 9: 427-429.

41. Eichhorn P, Sutsch G, Jenni R (1990) Congenital heart defects and abnormalities newly detected with echocardiography in adolescents and adults. Schweiz Med Wochenschr 120: 1697-1700. 